\title{
Research Paper: Sleep Quality, Anxiety, and Depression in Patients With Heart Failure
}

\author{
Hamid Aria ${ }^{1}$, Mohammad Mehdi Naghizadeh ${ }^{2^{*}}$ (D)
}

1. Bioinformatics and Computational Biology Research Center, Shiraz University of Medical Sciences, Shiraz, Iran.

2. Noncommunicable Disease Research Center, Fasa University of Medical Sciences, Fasa, Iran.

Citation: Aria H, Naghizadeh MM. Sleep Quality, Anxiety, and Depression in Patients With Heart Failure. JAMSAT. 2017;

3(4):213-220. https://doi.org/10.32598/jamsat.3.4.213

doi https://doi.org/10.32598/jamsat.3.4.213

Article info:

Received: 12 Jun 2017

Accepted: 05 Oct 2017

Keywords:

Sleep quality, Anxiety,

Depression, Heart failure

\section{ABSTRACT}

Objectives: Heart Failure (HF) is a chronic condition with great impact on the lifestyle of the patients. As many as $80 \%$ of HF patients report experiencing sleep difficulties. Thus, we try to detect clinical predictors of sleep quality and define probable relationship between anxiety, depression, and sleep quality in HF patients.

Materials \& Methods: One hundred patients (male: 50 persons, female: 50 persons) with ejection fraction less than $45 \%$ who were hospitalized in CCU and post-CCU ward, were included in this study. Hospital Anxiety and Depression Scale (HADS) and Pittsburg Sleep Quality Index (PSQI) questionnaire were used to collect the related data.

Results: The patients' mean (SD) total PSQI score was 9.07(4.43). The most problem was seen in sleep onset latency (1.85[1.15]) sub-score of PSQI and the sleep quality of $78 \%$ of patients was abnormal. This score was higher in patients with history of abnormal blood pressure $(P=0.001)$. $P S Q I$ score have significant correlation with anxiety $(r=0.216, P=0.035)$ as well as depression $(r=0.351, P=0.000)$.

Conclusion: Many HF patients suffer from sleep difficulties and PSQI score seems to have significant correlation with anxiety and depression.

\section{Introduction}

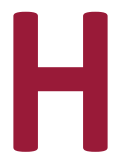

eart failure is a chronic condition that have great impact on the lifestyle of the patients [1]. The prevalence of Chronic Heart Failure (CHF) has been estimated to be $33 \%$ in Iran [2]. Sleep-related problems and poor sleep quality are significant public health issues with high prevalence worldwide that can adversely impact quality of life $[3,4]$. About $80 \%$ of HF patients also report experiencing sleep disturbances [5], including difficulties in falling asleep, insomnia, interrupted sleep (e.g. nocturia), restless sleep, and breathing difficulty during sleep [6-11]. Also poor sleep quality in HF is associated with decreased quality of life, depression, impaired self-care and increased risk for myocardial infarction [12-14]. Furthermore several studies have shown that insom-

* Corresponding Author: 
nia is related to anxiety and depression [15] and anxiety and major depressive disorder are associated with HF occurrence [16].

Recent controlled trials suggest that sleep disorders can increase mortality and risk for malignant arrhythmias in CHF patients [17-19]. Furthermore drugs used to treat $\mathrm{CHF}$ and cardiac resynchronization therapy are partially effective in the treatment of Central Sleep Apnea (CSA) or Cheyne Stokes Respiration (CSR) [20, 21]. Obstructive Sleep Apnea (OSA) is an established risk factor for hypertension [22] so increasing patient's cardiovascular risk profile. Moreover, OSA affects the heart directly by repetitive increase in Left Ventricular (LV) wall stress and decrease in LV performance [23, 24]. These findings suggest that OSA contributes to the pathogenesis of HF and might worsen HF symptoms.

Identification and treatment of SDB (sleep-disordered breathing) is imperative because an untreated sleep disorder intensifies the strain on the heart with increased respiratory effort, hypoxia, and sympathetic stimulation [25]. However, SDB still remains undiagnosed in numerous patients, much attention to ameliorate SDB may improve Ejection Fraction (EF) and outcomes for patients with systolic HF and decrease pulmonary artery pressure for those with preserved ejection fraction [26, 27]. Despite these findings, the factors that influence sleep quality in HF patients is contradictory $[6,8,28]$, suggesting that poor sleep quality in HF patients may be more complicated than already believed. Thus, assessment of sleep quality is important for a wide range of clinical and behavioral research fields and for practitioners of medicine and psychology [29]. Thus, this study aimed to detect clinical predictors of sleep quality and define probable relationships between anxiety, depression, and sleep quality in HF patients.

\section{Material and Methods}

This cross-sectional study was conducted at Vali-asr Hospital, an educational treatment base hospital in Fasa City, south of Iran from September 2012 to September 2013. Participants were hospitalized patients suffering from heart failure disease either in Coronary Care Unit (CCU) or post-CCU ward. This study included 100 patients (male: 50 persons, female: 50 persons) with ejection fraction less than $45 \%$ and all recruited patients filled the informed consent form. Also we took Ethics Committee approval.

Information of anxiety and depression, sleep quality, demographic and illness profile were gathered by an educated nurse via individual interviews. Demographic data in- cluded questions about age, gender, marital status and educational level. The information of illness profile included heart diseases risk factors, blood pressures and EF. Before asking questions, the patients' blood pressure were measured by sphygmomanometer in supine position. To screen anxiety and depression, we used the Hospital Anxiety and Depression Scale (HADS) [30] developed by Zigmond and Snaith in 1983 to identify cases of anxiety and depression among patients in nonpsychiatric hospital clinics.

HADS contains 14 items with two subscales: anxiety and depression. Each item has 4-point scale, giving maximum scores of 21 for anxiety and depression that high score indicate more anxiety and depression. Scores $\geq 11$ on either subscale are considered to be a significant 'case' of psychological morbidity, while scores of 8-10 represents 'borderline' and 0-7 'normal' [31]. Generally, the Iranian version of the HADS was found to be acceptable to almost all patients (99\%). Its Cronbach $\alpha$ reliability coefficient has been found to be 0.78 for the HADS anxiety sub-scale and 0.86 for the HADS depression sub-scale.

Sleep quality was assessed by Pittsburg Sleep Quality Index (PSQI). PSQI is a standardized self-administered questionnaire, introduced in 1989 and has gained widespread acceptance as a useful instrument for the assessment of sleep disorders that may be associated with anxiety and depression [32]. PSQI consists of seven clinically derived components that assesses the sleep difficulty, and the sum of these seven component scores yields a global score of subjective sleep quality (range: 0-21). PSQI Cronbach $\alpha$ coefficient was 0.77 for all subjects, 0.52 for the patient group, and 0.78 for the control group. Cronbach $\alpha$ value of 0.77 indicates acceptable reliability [33]. The validity assessment results suggest that the Persian version of the PSQI is an acceptable instrument.

Quantitative variables are presented as mean (SD) values and qualitative variables as frequency (percentage). PSQI scores were compared between groups with ANOVA. The Pearson correlation coefficient was used to analyze the relationship between PSQI sub-scores with anxiety, depression, and blood pressures. A multiple linear regression model was used to detect influential factors on sleep quality. Therefor in this model, all variables were included in the analysis. Entry and removal criteria for variables were set at $P$ values less than 0.05 . Finally variables that remains in the model, unstandardized regression coefficients with its standard errors were reported. Statistical analysis was done by using IBM (International Business Machines Corporation) SPSS (IBMSPSS Inc, Chicago, Illinois) version 19. P value less than 0.05 was considered as significant level. 


\section{Results}

\section{Patient's characteristics}

In this study, we enrolled $100 \mathrm{HF}$ patients (50 male and 50 female) with the mean (SD) age of was 66.80(13.07) year. About $48 \%$ of patients had history of blood pressure, $35 \%$ of them had positive history of MI (myocardial infarction), $22 \%$ were smoker and $71 \%$ were uneducated. Their mean (SD) anxiety and depression scores were $8.77(4.11)$ and 10.55(3.56), respectively.

\section{Sleep quality}

The patients' mean (SD) total PSQI score was 9.07(4.43). Also as referred in Table 2, the most problem in sub-scores of PSQI was observed in sleep onset latency (1.85[1.15]) and the least problem was observed in using sleeping medication (0.86[1.12]). Sleep quality of $22 \%$ of these patients was normal (PSQI score $<5$ ) and $78 \%$ abnormal. As showed in Table 1 , the mean (SD) PSQI score in male patients was 8.25(4.65) that was significantly lower than female scores, i.e. 10.22(3.88) $(P=0.031)$. This score was higher in patients with his- tory of abnormal blood pressure $(\mathrm{P}=0.001)$. Also $\mathrm{PSQ}$ total score is lowest in employed patients $(P=0.028)$. Total score of sleep quality index was not different in patients with $\mathrm{MI}$ history $(\mathrm{P}=0.157)$, with regard to smoking $(P=0.079)$, age $(P=0.687)$, and education $(P=0.602)$. EF did not have significant correlation with PSQI score ( $r=-0.026, P=0.805)$, systolic $B P(r=0.142, P=0.171)$ and diastolic $B P(r=0.069, P=0.510)$.

\section{Sleep quality and HADS}

PSQI score has significant correlation with anxiety $(r=0.216, P=0.035)$ and with depression ( $r=0.351, P=0.000)$. As showed in Figure 1 in people with depression difficulties, the mean PSQI score was higher significantly from who was healthy $(P=0.036)$ also in patients with anxiety $(P=0.029)$.

\section{Multivariate analysis}

Stepwise multiple regression analysis showed that three factors affect sleep quality (Table 3): 1 . Age, patient with higher age had better quality of sleep $(P=0.049), 2$. History of blood pressure, patients with this history had the worst quality of sleep $(\mathrm{P}=0.005)$, and 3 ) higher depression

Table 1. Mean of PSQI in patients with HF

\begin{tabular}{|c|c|c|c|c|c|}
\hline \multirow{2}{*}{ Characteristics } & & \multirow{2}{*}{$\mathbf{n}$} & \multicolumn{3}{|c|}{ PSQI Total Score (0-21) } \\
\hline & & & Mean & SD & $\mathbf{P}$ \\
\hline \multirow{2}{*}{ Sex } & Male & 50 & 8.25 & 4.65 & \multirow{2}{*}{0.031} \\
\hline & Female & 50 & 10.22 & 3.88 & \\
\hline \multirow{2}{*}{ Blood pressure $\mathrm{dx}$} & Normal & 52 & 7.62 & 4.5 & \multirow{2}{*}{0.001} \\
\hline & Abnormal & 48 & 10.65 & 3.81 & \\
\hline \multirow{2}{*}{ Myocardial infarction } & No & 65 & 8.59 & 4.35 & \multirow{2}{*}{0.157} \\
\hline & Yes & 35 & 9.94 & 4.53 & \\
\hline \multirow{2}{*}{ Smoking } & No & 78 & 9.34 & 4.46 & \multirow{2}{*}{0.104} \\
\hline & Yes & 22 & 7.57 & 3.93 & \\
\hline \multirow{4}{*}{ Age, $y$} & $39-49$ & 10 & 7.85 & 3.67 & \multirow{4}{*}{0.745} \\
\hline & $50-59$ & 27 & 9.61 & 3.54 & \\
\hline & $60-69$ & 18 & 8.35 & 4.14 & \\
\hline & $\geq 70$ & 45 & 8.87 & 4.71 & \\
\hline \multirow{2}{*}{ Educational level } & Illiterate & 71 & 9.12 & 4.17 & \multirow{2}{*}{0.602} \\
\hline & Educated & 29 & 8.59 & 5.00 & \\
\hline \multirow{3}{*}{ Job } & Employed & 46 & 7.55 & 4.42 & \multirow{3}{*}{0.028} \\
\hline & Unemployed & 15 & 8.91 & 4.87 & \\
\hline & Housekeeper & 39 & 10.17 & 3.92 & \\
\hline
\end{tabular}


Table 2. PSQI sub scores in HF patients

\begin{tabular}{|c|c|c|}
\hline Variable & Mean & SD \\
\hline Sleep quality (0-3) & 1.37 & 0.93 \\
\hline Sleep onset latency & 1.85 & 1.15 \\
\hline Sleep duration & 1.36 & 1.23 \\
\hline Sleep efficacy & 0.53 & 0.92 \\
\hline Sleep disturbance & 1.61 & 0.60 \\
\hline Using sleeping medication & 0.86 & 1.12 \\
\hline Daytime dysfunction & 1.46 & 0.96 \\
\hline Total PSQI (0-21) & 9.07 & 4.43 \\
\hline
\end{tabular}

JAMSAT

Table 3. Stepwise multiple regression analysis for sleep quality (PSQI total score) in CAD patients

\begin{tabular}{|c|c|c|c|c|}
\hline Variable & Regression Coefficient & Standard Error of Regression Coefficient & $\mathbf{t}$ & $\mathbf{P}$ \\
\hline Model Constant & 8.064 & 2.464 & 3.273 & 0.002 \\
\hline Blood Pressure $\mathrm{dx}$ & 2.583 & 0.890 & 2.903 & 0.005 \\
\hline Depression Score & 0.354 & 0.123 & 2.882 & 0.005 \\
\hline Age (y) & -0.067 & 0.035 & -1.915 & 0.049 \\
\hline
\end{tabular}

Adjusted $\mathrm{R}^{2}=0.210$.

JAMSAT

score that caused the worst sleep quality $(\mathrm{P}=0.005)$. Other variables were not included in the regression model.

\section{Discussion}

This study was conducted to identify some variables that affect sleep quality in patients with heart failure and we found that many patients with HF suf- fer from sleep disorders. Lee et al. reported that approximately $33 \%$ of individuals over 18 years had insomnia symptoms related to hypertension, stroke, stress, arthralgia, depression and urological disorder [34], also about $50 \%$ of stroke patients have sleep disorder [35]. Herrscher et al. found that $52 \%$ of patients with HF had moderate to severe sleep-disordered breathing [36].

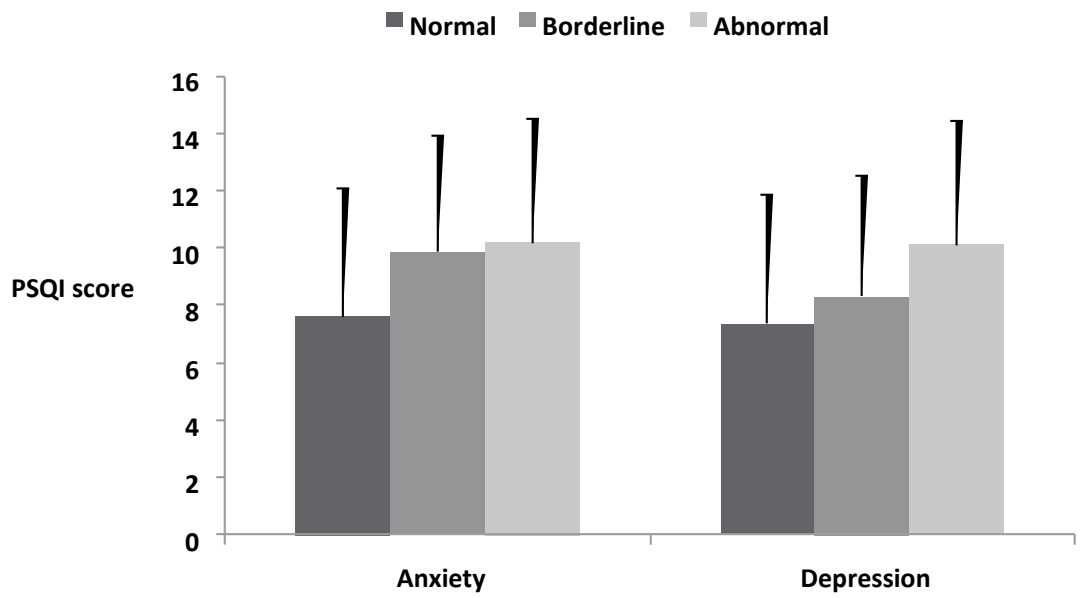

Figure 1. Sleep quality (PSQI total score) in CAD patients with anxiety and depression 
In our study we found that PSQI score has significant correlation with anxiety and depression in HF patients. But there is no association between PSQI score, and MI history or smoking. Also we realized that age, BP and depression play a significant role in worsening sleep quality. Herrscher et al. observed no association between sleepdisordered breathing and age or male gender [36]as we find too that older patients had better sleep quality but sleep quality had no association with gender. However, in some studies, the results demonstrate that sleep difficulties are prevalent in older adults with HF. A previous study has showed that demographic (such as older age) and medical factors (such as HF severity) are correlated with poor sleep quality in patients with $\mathrm{HF}$ [6].

Fritschi et al. observed that patients with HF are at considerable risk for sleep disturbances [32]. Herrscher et al. found that hypertension was a strong predictor of OSA (obstructive sleep apnea) among HF patients. Also they found that patients with CSA (central sleep apnea) have generally lower EF, lower cardiac output and at higher risk of developing lower blood pressure [36]. A critical review of the literature that was done between 1994-2009 reported that the prevalence of depression and anxiety in patients with chronic $\mathrm{HF}$ is $10 \%-60 \%$ and $11 \%-45 \%$, respectively [37]. Among the PSQI subscales, daytime dysfunction appeared to have the strongest relationship with anxiety disorders comorbid with poor quality sleep than poor mental health-related quality of life with anxiety disorders alone [38].

The exact underlying mechanism of depression in augmentation of HF is not clear, but it is possible that depression may reflect greater sleep disorders and so increase HF severity. According to finding of Haworth JE et al. study in 2005, depression and anxiety in patients with $\mathrm{CHF}$ was related to previous psychiatric history and a higher NYHA (New York Heart Association) class. Additionally, anxiety in CHF patients was related to comorbid physical illness (diabetes and angina). Furthermore, some studies suggest that the physical, psychological and social effects of depression negatively impact CHF whose symptoms may lead to depression, especially in lower social class, worse NHYA class, and those with a previous history of mental illness [39].

Another study commented that patients with CHF often have cerebrovascular diseases which affect small vessel functions and so vascular depression may occurr that leads to apathy, poor executive cognitive function, and psychomotor impairment [40]. In clarification of the mechanism of depression and anxiety in patients with $\mathrm{CHF}$, Yohannes, et al. reported that coronary artery dis- ease and high blood pressure can lead to CHF and CHF in individuals with low social class or in solitary young people can result in depression. Then depression in turn increases heart rate and arrhythmia and also decreases sleep time [37].

Future work that employs more objective assessments of sleep quality is needed to elucidate and confirm the current findings. Similar case controlled studies with larger samples that directly measure comorbid conditions and use precise instruments to study sleep disorders such as polysomnography or design cohort studies are much needed to better understand the independent effects of sleep quality in HF.

According to findings of our study, medical specialists, especially cardiologists in addition to control disease sign and symptoms, must attend to other factors such as sleep status and depression in HF patients, too. We recommend that physicians consult with psychiatrists in this situation specifically after patients' discharge, to increase their health condition and improve their sleep status.

\section{Conclusion}

The most HF patients have low sleep quality and PSQI score seems to have associated with anxiety and depression.

\section{Ethical Considerations}

Compliance with ethical guidelines

The study have been approved by the Research Ethics Committee. Informed consent was obtained from all individual participants included in the study.

\section{Funding}

This study was funded by Fasa University of Medical Sciences.

\section{Conflict of interest}

The authors declared that there is no conflicts of interest regarding the publication of this article.

\section{References}

[1] Rector TS, Anand IS, Cohn JN. Relationships between clinical assessments and patients' perceptions of the effects of heart failure on their quality of life. Journal of Cardiac Failure. 2006; 12(2):8792. [DOI:10.1016/j.cardfail.2005.10.002] [PMID] 
[2] Rahnavard Z, Zolfaghari M, Kazemnejad A, Hatamipour K. [An investigation of quality of life and factors affecting it in the patients with congestive heart failure (Persian)]. Hayat. 2006; 12(1):77-86.

[3] Suleiman KH, Yates BC, Berger AM, Pozehl B, Meza J. Translating the Pittsburgh sleep quality index into Arabic. Western Journal of Nursing Research. 2010; 32(2):250-68. [DOI:10.1177/0193945909348230] [PMID]

[4] Go AS, Mozaffarian D, Roger VL, Benjamin EJ, Berry JD, Blaha MJ, et al. Heart disease and stroke statistics--2014 update: A report from the American Heart Association. Circulation. 2014 129(3):e28-e292. [DOI:10.1161/01.cir.0000441139.02102.80]

[5] Tremel F, Pepin J, Veale D, Wuyam B, Siche J, Mallion J, et al. High prevalence and persistence of sleep apnoea in patients referred for acute left ventricular failure and medically treated over 2 months. European Heart Journal. 1999; 20(16):1201-9. [DOI:10.1053/euhj.1999.1546] [PMID]

[6] Wang TJ, Lee SC, Tsay SL, Tung HH. Factors influencing heart failure patients' sleep quality. Journal of Advanced Nursing. 2010; 66(8):1730-40. [DOI:10.1111/j.1365-2648.2010.05342.x] [PMID]

[7] Santos MAd, Guedes EdS, Barbosa RL, Cruz DdALM. Sleeping difficulties reported by patients with heart failure. Revista LatinoAmericana de Enfermagem. 2012; 20(4):644-50. [DOI:10.1590/ S0104-11692012000400003]

[8] Erickson VS, Westlake CA, Dracup KA, Woo MA, Hage A. Sleep disturbance symptoms in patients with heart failure. AACN Clinica Issues. 2003; 14(4):477-87. [DOI:10.1097/00044067-20031100000009] [PMID]

[9] Redeker NS. Sleep disturbance in people with heart failure: implications for self-care. The Journal of Cardiovascular Nursing. 2008; 23(3):231-8. [DOI:10.1097/01.JCN.0000305094.20012.76] [PMID]

[10] Redeker NS, Stein S. Characteristics of sleep in patients with stable heart failure versus a comparison group. Heart \& Lung The Journal of Critical Care. 2006; 35(4):252-61. [DOI:10.1016/j. hrtIng.2005.10.007] [PMID]

[11] Redeker NS, Muench U, Zucker MJ, Walsleben J, Gilbert M, Freudenberger $R$, et al. Sleep disordered breathing, daytime symptoms, and functional performance in stable heart failure. Sleep. 2010; 33(4):551-60. [DOI:10.1093/sleep/33.4.551] [PMID] [PMCID]

[12] Garcia S, Alosco ML, Spitznagel MB, Cohen R, Raz N, Sweet L, et al. Poor sleep quality and reduced cognitive function in persons with heart failure. International Journal of Cardiology. 2012; 156(2):248-9. [DOI:10.1016/j.ijcard.2012.01.037] [PMID] [PMCID]

[13] Izawa K, Watanabe S, Oka K, Hiraki K, Morio Y, Kasahara Y, et al. Relation between sleep quality and physical activity in chronic heart failure patients. Recent Patents on Cardiovascular Drug Discovery. 2011; 6(3):161-7. [DOI:10.2174/157489011797377004]

[14] Selim B, Won C, Yaggi HK. Cardiovascular consequences of sleep apnea. Clinics in Chest Medicine. 2010; 31(2):203-20. [DOI:10.1016/j.ccm.2010.02.010] [PMID]

[15] Alvaro PK, Roberts RM, Harris JK. A systematic review assessing bidirectionality between sleep disturbances, anxiety, and depression. Sleep. 2013; 36(7):1059-68. [DOI:10.5665/sleep.2810] [PMID] [PMCID]

[16] Garfield LD, Scherrer JF, Hauptman PJ, Freedland KE, Chrusciel $\mathrm{T}$, Balasubramanian S, et al. Association of anxiety disorders and depression with incident heart failure. Psychosomatic Medicine.
2014; 76(2):128. [DOI:10.1097/PSY.0000000000000027] [PMID] [PMCID]

[17] Bitter T, Westerheide N, Prinz C, Hossain MS, Vogt J, Langer C et al. Cheyne-Stokes respiration and obstructive sleep apnoea are independent risk factors for malignant ventricular arrhythmias requiring appropriate cardioverter-defibrillator therapies in patients with congestive heart failure. European Heart Journal. 2011; 32(1):61-74. [DOI:10.1093/eurheartj/ehq327] [PMID]

[18] Javaheri S, Shukla R, Zeigler H, Wexler L. Central sleep apnea, right ventricular dysfunction, and low diastolic blood pressure are predictors of mortality in systolic heart failure. Journa of the American College of Cardiology. 2007; 49(20):2028-34. [DOI:10.1016/j.jacc.2007.01.084] [PMID]

[19] Wang H, Parker JD, Newton GE, Floras JS, Mak S, Chiu K-L, et al. Influence of obstructive sleep apnea on mortality in patients with heart failure. Journal of the American College of Cardiology. 2007; 49(15):1625-31. [DOI:10.1016/j.jacc.2006.12.046] [PMID]

[20] Bradley TD, Logan AG, Kimoff RJ, Series F, Morrison D, Ferguson $\mathrm{K}$, et al. Continuous positive airway pressure for central sleep apnea and heart failure. The New England Journal of Medicine. 2005; 353(19):2025-33. [DOI:10.1056/NEJMoa051001] [PMID]

[21] Luthje L, Renner B, Kessels R, Vollmann D, Raupach T, Gerritse B, et al. Cardiac resynchronization therapy and atrial overdrive pacing for the treatment of central sleep apnoea. European Journal of Heart Failure. 2009; 11(3):273-80. [DOI:10.1093/eurjhf/hfn042] [PMID] [PMCID]

[22] Nieto FJ, Young TB, Lind BK, Shahar E, Samet JM, Redline S, et al. Association of sleep-disordered breathing, sleep apnea, and hypertension in a large community-based study. Sleep Heart Health Study. JAMA. 2000; 283(14):1829-36. [DOI:10.1001/ jama.283.14.1829] [PMID]

[23] Orban M, Bruce CJ, Pressman GS, Leinveber P, Romero-Corral A Korinek J, et al. Dynamic changes of left ventricular performance and left atrial volume induced by the mueller maneuver in healthy young adults and implications for obstructive sleep apnea, atrial fibrillation, and heart failure. The American Journal of Cardiology. 2008; 102(11):1557-61. [DOI:10.1016/j.amjcard.2008.07.050] [PMID] [PMCID]

[24] Romero-Corral A, Somers VK, Pellikka PA, Olson EJ, Bailey KR, Korinek J, et al. Decreased right and left ventricular myocardial performance in obstructive sleep apnea. Chest. 2007; 132(6):186370. [DOI:10.1378/chest.07-0966] [PMID]

[25] Valdivia-Arenas MA, Powers M, Khayat RN. Sleep-disordered breathing in patients with decompensated heart failure. Heart Failure Reviews. 2009; 14(3):183-93. [DOI:10.1007/s10741-0089103-0] [PMID] [PMCID]

[26] Bitter T, Faber L, Hering D, Langer C, Horstkotte D, Oldenburg 0. Sleep-disordered breathing in heart failure with normal left ventricular ejection fraction. European Journal of Heart Failure. 2009; 11(6):602-8. [DOI:10.1093/eurjhf/hfp057] [PMID]

[27] Khayat R, Small R, Rathman L, Krueger S, Gocke B, Clark L, et al. Sleep-disordered breathing in heart failure: Identifying and treating an important but often unrecognized comorbidity in heart failure patients. Journal of Cardiac Failure. 2013; 19(6):431-44. [DOI:10.1016/j.cardfail.2013.04.005] [PMID] [PMCID]

[28] Parker KP, Dunbar SB. Sleep and heart failure. Journal of Cardiovascular Nursing. 2002; 17(1):30-41. [DOI:10.1097/00005082 200210000-00004] 
[29] Moghaddam JF, Nakhaee N, Sheibani V, Garrusi B, Amirkafi A Reliability and validity of the Persian version of the Pittsburgh Sleep Quality Index (PSQI-P). Sleep and Breathing. 2012; 16(1):7982. [DOI:10.1007/s11325-010-0478-5] [PMID]

[30] Herrmann C. International experiences with the Hospital Anxiety and Depression Scale: A review of validation data and clinical results. Journal of Psychosomatic Research. 1997; 42(1):17-41. [DOI:10.1016/S0022-3999(96)00216-4]

[31] Zigmond AS, Snaith RP. The hospital anxiety and depression scale. Acta Psychiatrica Scandinavica. 1983; 67(6):361-70. [DOI:10.1111/j.1600-0447.1983.tb09716.x]

[32] Fritschi C, Redeker NS. Contributions of comorbid diabetes to sleep characteristics, daytime symptoms, and physical function among patients with stable heart failure. The Journal of Cardiovascular Nursing. 2015; 30(5):411-9. [DOI:10.1097/ JCN.0000000000000183] [PMID] [PMCID]

[33] Farrahi Moghaddam J, Nakhaee N, Sheibani V, Garrusi B, Amirkafi A. Reliability and validity of the Persian version of the Pittsburgh Sleep Quality Index (PSQI-P). Sleep and Breathing. 2012; 16(1):79-82. [DOI:10.1007/s11325-010-0478-5] [PMID]

[34] Lee S, Cheong YS, Park EW, Choi EY, Yoo HK, Kang KH, et al. Prevalence of sleep disorder and associated factors in family practice. Korean Journal of Family Medicine. 2010; 31(11):837-44. [DOI:10.4082/kjfm.2010.31.11.837]

[35] Chung WS, Lin CL, Chen YF, Chiang JY, Sung FC, Chang YJ, et al. Sleep disorders and increased risk of subsequent acute coronary syndrome in individuals without sleep apnea: A nationwide population-based cohort study. Sleep. 2013; 36(12):1963-8. [DOI:10.5665/sleep.3240] [PMID] [PMCID]

[36] Herrscher TE, Akre H, Overland B, Sandvik L, Westheim AS. Clinical predictors of sleep apnoea in heart failure outpatients. International Journal of Clinical Practice. 2014; 68(6):725-30. [DOI:10.1111/ijcp.12396] [PMID]

[37] Yohannes AM, Willgoss TG, Baldwin RC, Connolly MJ. Depression and anxiety in chronic heart failure and chronic obstructive pulmonary disease: Prevalence, relevance, clinical implications and management principles. International Journal of Geriatric Psychiatry. 2010; 25(12):1209-21. [DOI:10.1002/gps.2463] [PMID]

[38] Ramsawh HJ, Stein MB, Belik SL, Jacobi F, Sareen J. Relationship of anxiety disorders, sleep quality, and functional impairment in a community sample. Journal of Psychiatric Research. 2009; 43(10):926-33. [DOI:10.1016/j.jpsychires.2009.01.009] [PMID]

[39] Haworth JE, Moniz-Cook E, Clark AL, Wang M, Waddington R, Cleland JG. Prevalence and predictors of anxiety and depression in a sample of chronic heart failure patients with left ventricular systolic dysfunction. European Journal of Heart Failure. 2005; 7(5):803-8. [DOI:10.1016/j.ejheart.2005.03.001] [PMID]

[40] Alexopoulos GS, Meyers BS, Young RC, Campbell S, Silbersweig D, Charlson M. 'Vascular depression' hypothesis. Archives of General Psychiatry. 1997; 54(10):915-22. [DOI:10.1001/ archpsyc.1997.01830220033006] [PMID] 
